\title{
BRIDGING THE GAP OF SKILLED SURGEONS IN LOW AND MIDDLE INCOME COUNTRIES USING ICT BASED TOOLS: A CASE STUDY IN SUPER-SPECIALITY TRAINING
}

\author{
Sanjay Kumar Yadav MS ${ }^{1}$, Saroj Kanta Mishra MS ${ }^{1,2}$, AK Mohanty MS ${ }^{3}$, Anjali Mishra MS, PDC ${ }^{1}$, \\ BN Mohanty MS $^{3}$
}

${ }^{1}$ Department of Endocrine Surgery, Sanjay Gandhi Postgraduate Institute of Medical Sciences, Lucknow, India

${ }^{2}$ School of Telemedicine and Biomedical informatics, Sanjay Gandhi Postgraduate Institute of Medical Sciences, Lucknow, India

${ }^{3}$ Department of Endocrine Surgery, SCB Medical College, Cuttack, Odisha, India

\begin{abstract}
Introduction: Over the last two decades, advancement of super specialised surgical disciplines has shown improved health outcome, in particular quality and safety. Although medical technology has developed to meet diagnostics and therapeutic needs, there is a scarcity of trained human resources in advanced specialities in low and middle income countries (LMICs). Innovative methods are needed to educate and train people at their workplaces using collaborative technologies and networks. Methods: Over the last 15 years, two general surgeons in Cuttack have been telementored from Lucknow 1,163 $\mathrm{km}$ away, using collaborative technologies to develop Endocrine Surgery. This study reviews the last 11 years of the service which includes a clinical decision support system and treatment planning advice using real time videoconferencing. Results: Over the last 11 years, 199 endocrine surgeries per annum were performed with most being thyroid cases as compared with 119 surgeries per annum during the previous five years. Parathyroid and adrenal cases increased significantly during this period ( $\mathrm{p}<0.001)$. Rates of temporary and permanent vocal cord palsy $(1.7 \%$ and $0 \%)$, hypocalcaemia (5.9\% and $1.1 \%$ ) were comparable with high volume centres. Based on the quantum, safety and quality outcome of endocrine surgery the provincial government has approved creation of a super-speciality department of endocrine surgery in Cuttack. Conclusion: Sustained engagement using telementoring can transfer surgical skills to needy surgeons and enable them to match the expertise of mentors. This model can be replicated in other specialities in a cost effective way to develop specialised human resources for healthcare, in particular in LMICs.
\end{abstract}

Keywords: telemedicine; LMIC; telementoring; endocrine surgery; videoconference; India

Yadav SK, et al. JISfTeH 2018;6:e22(1-6).

doi: 10.29086/JISfTeH.6.e22

Open access, published under Creative Commons Attribution 4.0 BY International Licence

Copyright: The authors

\section{Introduction}

Telementoring is a mode of remote assistance carried out using digital network technology and information systems. ${ }^{1}$ This tool was first pioneered by educational institutions and has led the way to the development of e-mentoring programmes. ${ }^{2}$ In particular, these programmes have been flourishing in school settings in both the United Kingdom and North America. ${ }^{3}$ In recent times, many reports have been published describing use of telementoring in various fields of surgery mostly in developed world. ${ }^{4-6}$ Talbot et al. reported that surgical telementoring may enable physicians to safely perform two-incision leg fasciotomy in remote environments and this could improve the chances of limb salvage when compartment syndrome occurs far from surgical care. ${ }^{7}$ Bilgic et al. reviewed the effectiveness of surgical telementoring with on-site mentoring and concluded that telementoring is associated with similar complication rates and operative times compared with on-site mentoring.

There are several definitions of telemedicine, but a commonly used definition adopted by the World Health Organization is, "The delivery of health care services, where distance is a critical factor, by all health care professionals using information and communication technologies for the exchange of valid information for diagnosis, treatment and prevention of disease and injuries, research and evaluation, and for the continuing education of health care providers, all in the interests of advancing the health of individuals and their communities." 8

In our context telementoring is assistance during the preoperative phase in diagnosis, decision making, treatment planning and preparing the road map for the operative 
procedure including in-theatre intra-operative advice when necessary. Telementoring was limited to complex procedures as over the years mentees have become more confident in handling complex cases with a reduction in assistance seeking behaviour. Apart from case based assistance, the focus now is more on continued enhancement of knowledge of the mentees through tele-education by seminars, exchange of academics and live broadcast of surgical workshops. This type of collaboration may be more appropriate than conventional telementoring in low and middle income countries (LMICs). However, the level of evidence to support the effectiveness of telementoring as a training tool is limited. ${ }^{9}$

Lee et al. described a novel intraoperative real-time training module, the Advanced Robotic Multi-display Educational System (ARMES). They successfully performed a robotic distal subtotal gastrectomy with D2 lymphadenectomy for a patient with gastric cancer employing this new teaching method without any transfer errors or system failures. Using this technique, the total operative time was $197 \mathrm{~min}$ and blood loss was $50 \mathrm{~mL}$ and there were no intra- or post-operative complications. ${ }^{10} \mathrm{~A}$ SAGES multi-institutional quality improvement initiative for sleeve gastrectomy via telementoring showed it to be feasible, practical, and successful, and was highly rated in this study by both the mentors and mentees. ${ }^{11}$ As is seen, there is ample literature regarding surgical telementoring in developed countries. However such experience is limited in LMICs.

Over the last two decades the advancement of superspecialised surgical disciplines has shown improved health outcome, in particular quality and safety. Though the technology has developed enough to meet the demand of diagnostics and therapeutic needs, there is scarcity of surgeons trained in such advanced specialities to cater for these services in LMICs. Traditional fellowship programmes offered by advanced medical institutions are difficult to obtain due to limited number of positions and large financial burden for the trainee. There is a need to develop innovative methods to educate and train surgeons at their workplace adopting collaborative technologies and networks which are universally available and robust enough to support remote training and skill development. There are few reports from LMICs where telementoring technologies have been used for capacity building. The positive impact of e-education in the field paediatric surgery has been reported and videoconferencing is now well established in the field of post graduate medical education. ${ }^{12,13}$ Authors have earlier reported the positive outcome of real time telementoring in improving quality and safety of surgical procedures. ${ }^{14}$

In 2001, a telementoring programme was initiated between the Sanjay Gandhi Post-Graduate Institute of Medical Sciences (SGPGIMS) Lucknow, Uttar Pradesh state, India, and the department of surgery at the Shri Ramachandra Bhanj Medical College (SCBMC), Cuttack,
Odisha state, 1,163 km away. (Figure 1) The first five years of this programme has been previously reported. ${ }^{14}$ The objective of this study was to review the long term outcome of the next 11 years of this sustained collaboration which included a clinical decision support system and treatment planning using an interactive real time videoconference system over high speed Internet network provided by National Knowledge Network (NKN). ${ }^{15}$

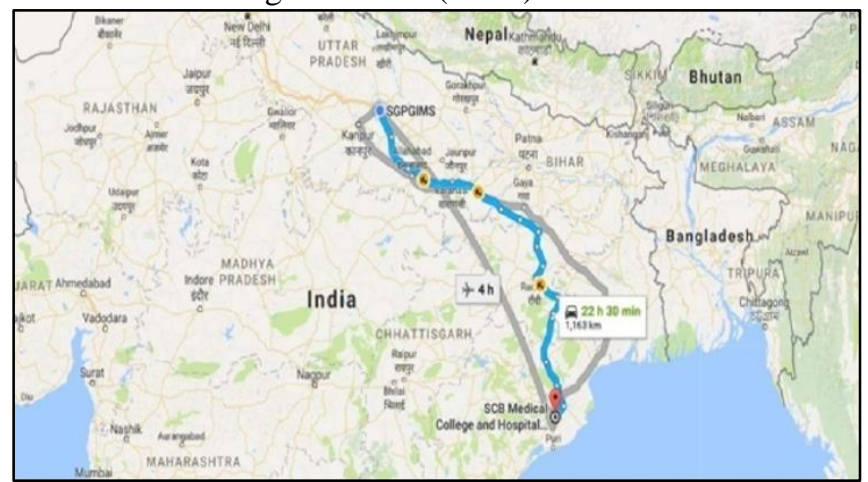

Figure 1. Distance between the two centres.

\section{Methods}

In 1998, two general surgeons with a special interest in endocrine surgery from the department of surgery, SCBMC, India registered at SGPGIMS for a three month short course training in endocrine surgery. Thereafter they remained in constant touch with SGPGIMS via telemedicine and telementoring technologies were used to develop their endocrine surgery expertise. ${ }^{14}$ These included a clinical decision support system, treatment planning, imaging and pathology review, and tele-CME workshops. Transmission of digital patient records consisting of the case history and investigation data (including radiologic films) followed by an interactive real time videoconference interaction between mentees and mentors constituted the technical steps in each of these modules. (Figure 2, 3 and 4) During tele-continuing medical education workshops (tele-CME) transmission of digital patient records consisting of the case history and investigation data (including radiologic films) followed by an interactive real time videoconference interaction between

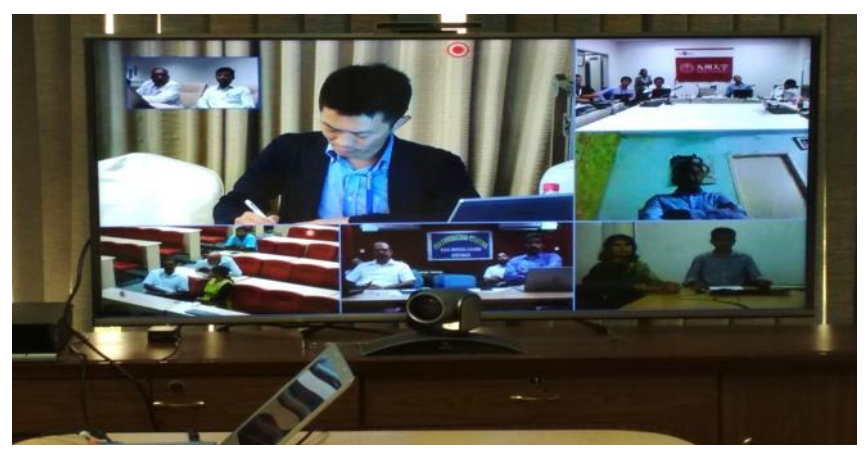

Figure 2. Real time broadcast of international telesession with SCBMC. 


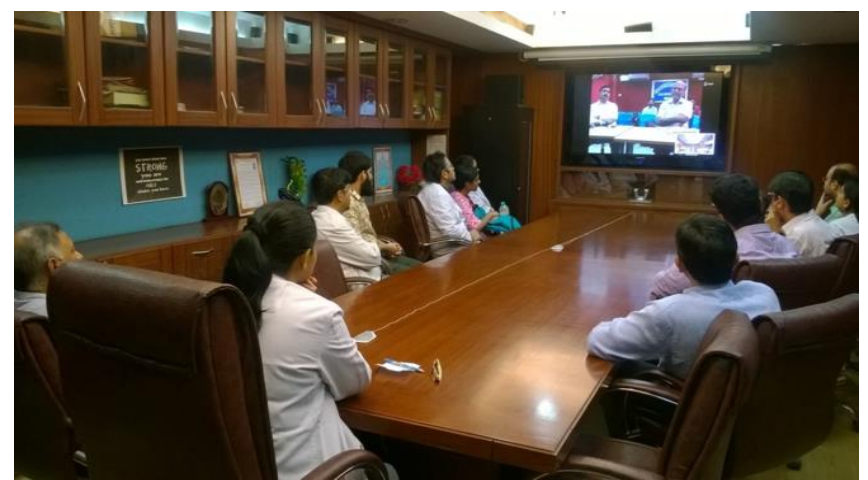

Figure 3. Tele-education session with SCBMC Cuttack.

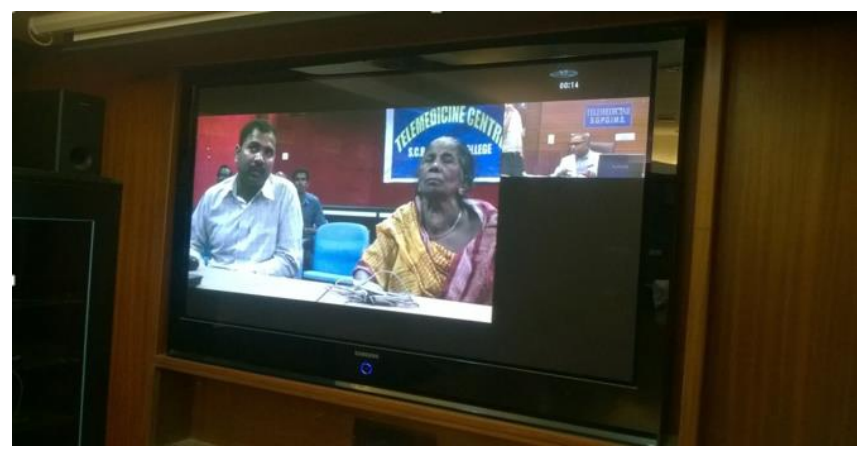

Figure 4. Clinical decision support system.

mentees and mentors constituted the technical steps in each of these modules. During tele-CME workshop sessions, PowerPoint slide exchanges along with interactive real time videoconference lectures and live surgery demonstrations from SGPGIMS Lucknow were carried out. Mentors also provided real time technical support during a complex surgery at Cuttack if it was sought from the mentees. It was infrequent and was needed approximately once a month. The outcome analysis was based on log-book records maintained prospectively at both ends. The first part of the project (Phase I: 2001-2005) has been reported. ${ }^{14}$ Data from the second phase (2006-2016) is analysed and presented here. Variables for number of surgical cases and complications were recorded from hospital case files, electronic case records and outpatient clinic. Data on tele-education sessions, real time consultations and seminars were collected from a log book maintained at both centres. The Z-test of proportions was applied to assess changes in the number of endocrine surgical cases performed by the mentees. Alpha was set at 5\%.

\section{Results}

There was an increase in the total number of endocrine surgical cases operated on over the years and a significant increase in parathyroid and adrenal surgery. (Table 1)

Table 1. Profile and average number of cases per annum in the two phases of study.

\begin{tabular}{|l|c|c|c|}
\hline $\begin{array}{l}\text { Average } \\
\text { surgeries } \\
\text { per annum }\end{array}$ & $\begin{array}{c}\text { Phase I } \\
(\mathbf{2 0 0 1 - 2 0 0 5 )}\end{array}$ & $\begin{array}{c}\text { Phase II } \\
(\mathbf{2 0 0 6 - 2 0 1 6 )}\end{array}$ & $\mathbf{p}$ \\
\hline Thyroid & 116 & 191 & $\mathrm{~ns}$ \\
\hline Parathyroid & 0.8 & 4 & $<0.001$ \\
\hline Adrenal & 2 & 4 & $<0.001$ \\
\hline
\end{tabular}

\section{Complications}

These cases were operated on with the same safety and quality results as high volume centres, and surgeons' confidence increased handling difficult cases. The result of surgical complications can be compared to standard acceptable figures reported by super-specialised centres including the mentoring institution. (Table 2) This observation testifies the confidence of mentees in identifying and preserving recurrent laryngeal nerves and parathyroid glands.

Improvement in the quality of video conference

In initial phase, the connectivity was through satellite based communication system with a $384 \mathrm{kbs}^{-1}$ bandwidth obtained from the Indian Space Research Organization (ISRO). During this phase NKN provided high speed Internet with an average bandwidth $2 \mathrm{mbs}^{-1}$ over an optical fibre backbone boosting the quality of the interactive video communication. Creation of endocrine surgery department:

Based on the quantum of work done in the field of endocrine

Table 2. Comparison of rate of complications between two phases of study period (RLN= Recurrent laryngeal nerve).

\begin{tabular}{|c|c|c|c|c|}
\hline Parameter & $\begin{array}{c}\text { Phase I } \\
(2001-2005)\end{array}$ & $\begin{array}{c}\text { Phase II } \\
(2006-2016)\end{array}$ & $\begin{array}{c}\begin{array}{c}\text { Reported rate } \\
\text { from }\end{array} \\
\text { SGPGIMS } \\
\end{array}$ & \begin{tabular}{|c|}
$\begin{array}{c}\text { Standard reported rate } \\
\text { from Super-specialised } \\
\text { centres }\end{array}{ }^{17,20}$ \\
\end{tabular} \\
\hline RLN identification rate & 99.3 & 99.5 & & \\
\hline $\begin{array}{l}\text { Vocal cord palsy } \\
\text { Temporary } \\
\text { Permanent }\end{array}$ & $\begin{array}{l}2 \\
0\end{array}$ & $\begin{array}{l}1 \\
0\end{array}$ & $\begin{array}{l}2.7 \% \\
0.8 \%\end{array}$ & $\begin{array}{l}1.0-1.6 \% \\
0.2-1.0 \%\end{array}$ \\
\hline $\begin{array}{l}\text { Hypocalcaemia } \\
\text { Temporary } \\
\text { Permanent } \\
\end{array}$ & $\begin{array}{l}5 \% \\
2 \% \\
\end{array}$ & $\begin{array}{r}5 \% \\
<1 \% \\
\end{array}$ & $\begin{array}{r}11.4 \% \\
1.4 \% \\
\end{array}$ & $\begin{array}{l}5-38.9 \% \\
0.3-1.8 \%\end{array}$ \\
\hline $\begin{array}{l}\text { Parathyroid surgery } \\
\text { Failure rate } \\
\text { RLN injury }\end{array}$ & $\begin{array}{l}1 \% \\
0\end{array}$ & $\begin{array}{l}1 \% \\
0\end{array}$ & & \\
\hline
\end{tabular}


surgery with safe and quality outcome the provincial government approved the creation of dedicated department of Endocrine Surgery at Cuttack with the two mentees as its faculty members in 2016.

\section{Discussion}

Currently, the world's population is growing by 1.2 per cent per year, or approximately an additional 83 million people annually. It is projected to increase by more than one billion people within the next 15 years, reaching 8.5 billion in 2030 , and increasing further to 9.7 billion in 2050 and 11.2 billion by $2100 .{ }^{21}$ During 2015-2050, half of the world's population growth is expected to be concentrated in nine countries: India, Nigeria, Pakistan, Democratic Republic of the Congo, Ethiopia, United Republic of Tanzania, United States of America, Indonesia and Uganda, listed according to the size of their contribution to the total growth. ${ }^{21}$ All of them being LMICs, except USA.

Etzioni et $a l^{22}$ have reported that as a result of an expanding/ageing population, there will be a $31 \%$ increase in surgical work between 2001 and 2020. The current and projected global demand for both general surgeons and specialist surgeons is increasing substantially, as is the superior clinical and economic outcome associated with high-volume surgeons in many specialties, including endocrine surgery. ${ }^{23-25}$ Due to this increase in demand for trained specialists, novel ways of surgical education should be explored. Surgical telementoring may be a solution to this global problem especially for low and middle income countries.

One of the authors (S.K.M.) has, through a research grant from the Department of Information Technology, Ministry of Communication and IT, Government of India, established a telemedicine infrastructure at the SCB Medical College, Cuttack in 2001. The idea was conceived to develop the expertise of endocrine surgery in the background of general surgery by imparting initial short term physical training followed by long term sustained engagement using telemedicine. The initial scope "testing the proof of concept" was aimed at the feasibility of telemedicine technology application in clinical care, which led to the development of several modules relating to clinical telemedicine (diagnostic and therapeutics) and education. ${ }^{14}$ Continuous reinforcement via telemedicine lead to specific interest in further training and academic activity by the department. Conferences specific to endocrine surgery were constantly being organised by the mentee institution. Major conferences organised by the mentee institution during past 10 years were the $6^{\text {th }}$ Annual Conference of Indian Association of Endocrine Surgeons (IAESCON-2005), and the $14^{\text {th }}$ Annual Conference of Indian Association of Endocrine Surgeons in 2013.

In recent years telementoring has emerged as a viable method of enhancing general surgical education and has been carried over to the surgical subspecialties. The first successful use of telementoring was reported by Ranshaw et al. $^{25}$ who telementored a rural surgeon in more than 24 cases of laparoscopic herniorrhaphy, all of which were completed successfully. Since then this approach has gained momentum with reproducible outcome reported by large number of studies especially in laparoscopic surgeries. ${ }^{4-6,26,27}$

Telementoring has been reported in low and middle income countries in West Africa ${ }^{12}$ and in other developing nations such as Brazil ${ }^{28,29}$ and South Africa. ${ }^{30,31}$ Most have used videoconferencing for tele-education and although doubts have been expressed regarding the sustainability of telecommunication based healthcare activities in the developing world, tele-education is a viable option even in remote places. ${ }^{12,13}$

Videoconferenced tele-education has been widely used in KwaZulu-Natal, South Africa since 2001..$^{30,31}$ The number of programmes and activities participating in videoconferenced teaching has increased over the years and has improved access to education and training in resource constrained settings. ${ }^{31}$ The case study of the University of KwaZuluNatal tele-education programme is somewhat similar to our report where continued collaboration has led to a fruitful impact.

Similarly the evaluation of the feasibility, potential, problems and risks of an Internet-based telemedicine network in developing countries of Western Africa was undertaken by RAFT project and it was reported that telemedicine tools have an important role to play in the improvement of the quality and efficiency of health systems in developing countries. ${ }^{32}$ Stolyar et al. in Russia have used online transmissions from the operating rooms, as well as interactive master classes with full interactive communication between the remote audience and the operating surgeon and monitoring the progress of the operation using a number of video cameras in the operating room to improve clinical skills of participating physicians. ${ }^{33}$

In Brazil, Oliviera et al. have reported on the Unified Health System (UNA-SUS) lead Technology Enhanced Learning (TEL) for distance education foro the Brazilian health workforce. In a resource limited setting, the demand of professional education is being provided by the TEL and from March 2008 to October 2015 (91months), UNA-SUS had 206,834 enrolments in 40 specialisation courses and 60 qualification courses, reaching 119,109 professionals. ${ }^{28}$ Recognising dentistry as a primary healthcare component, UNA-SUS developed applications for this specific area providing relevant information to the various professionals who provide primary care services in dental care within the healthcare network. ${ }^{29}$ RUTE (Rede Universitaria de Telemedicina), another Brazilian Telemedicine University Network programme launched its 118th Telemedicine Unit, all of them located in university and teaching hospitals in the 27 Brazilian states in September 2015. Fifty-five special interest groups (SIGs) in health specialties operate over the 
collaborative network model with two to three scientific videoconferenced sessions every day, amongst 150 participating institutions. ${ }^{34}$ This and similar other examples around the world are transforming the way healthcare is applied, managed, monitored and evaluated.

Our report is probably the first successful use of telemedicine technology in telementoring in a sustained manner over a 16 years period which has led to creation of a new endocrine surgery department in the mentee institution. Furthermore, familiarity and experience with telemedicine technology has resulted in an institutional infrastructure in telemedicine in the province of Odisha, connecting medical colleges. The cost-effectiveness of establishing telemedicine in developing country set up, is a common and valid question asked by the opponents of telemedicine. The technology has become cheaper and more easily available, even in LMICs being supported by the respective governments.

We must understand that telemedicine is not a different medical practice but it is merely a tool to assist in medical practice. In this situation, the knowledge and clinical experience of consultants adds something that empowers the mentee leading to better patient management and outcome.

This paper reflects our experience of telementoring and telemedicine in a developing country. We started in a small way and evaluated the pilot project, reported positive outcomes and finally sustained activity for over 15 years leading to the creation of the new and only department of endocrine surgery of the Odisha state.

\section{Conclusion}

The study has established that sustained engagement using telemedicine based telementoring approach can improve knowledge and understanding of the needy surgeons and enable them to match the expertise of mentors. This model can be replicated in number of locations and other specialities and is a cost effective way of developing specialised human resources.

\author{
Corresponding author: \\ S.K. Mishra \\ Dept. of Endocrine Surgery \\ Nodal Officer, SGPGI Telemedicine Programme \\ Sanjay Gandhi PG Inst. of Medical Sciences \\ Lucknow, India - 226014 \\ Tel: +91 (0522) 2494409, 2495200 \\ Fax: +91 (0522) 2668777 \\ E-Mail: skmishra@sgpgi.ac.in, \\ skmishra_1956@yahoo.com
}

Conflict of interest. The authors declare no conflicts of interest.
Acknowledgments This study is part of the research and development projects carried out under the SGPGI Telemedicine Programme. The Ministry of Electronics and Information Technology, Government of India, supported the project through National Knowledge Network.

Ethical approval: All procedures performed in studies involving human participants were in accordance with the ethical standards of the institutional and/or national research committee and with the 1964 Helsinki declaration and its later amendments or comparable ethical standards.

\section{References}

1. Kasprisin CA, Boyle SP, Single RM, Muller CB. Building a better bridge: testing etraining to improve e-mentoring programmes in higher education. Mentor Tutoring 2003;11(1):67-78. https://doi.org/10.1080/1361126032000054817

2. Bierema L, Merriam S. E-mentoring: Using computer mediated communication to enhance the mentoring process. Innov High Educ 2002;26(3):211-227. https://doi.org/10.1023/A:1017921023103

3. Russell A, Perris K. Telementoring in community nursing: a shift from dyadic to communal models of learning and professional development. Mentor Tutoring 2003;11(2):227-237. https://doi.org/10.1080/13611260306856

4. Bruschi M, Micali S, Porpiglia F, et al. Laparoscopic telementored adrenalectomy: the Italian experience. Surg Endosc 2005;19(6):836-840. https://doi.org/10.1007/s00464-004-9124-2

5. Rosser JC, Wood M, Payne JH, et al. Telementoring: a practical option in surgical training. Surg Endosc 1997;11(8):852-855. https://doi.org/10.1007/s004649900471

6. Challacombe B, Kandaswamy R, Dasgupta P et al. Telementoring facilitates independent hand-assisted laparoscopic living donor nephrectomy. Transplant Proc 2005:37(2):613-616. https://doi.org/10.1016/j.transproceed.2005.01.065

7. Talbot M, Harvey EJ, Berry GK, et al. A pilot study of surgical telementoring for leg fasciotomy. J R Army Med Corps 2018;164(2):83-86. http://dx.doi.org/10.1136/jramc-2017-000817

8. World Health Organization. A health telematics policy in support of WHO's Health-For-All strategy for global health development: report of the WHO group consultation on health telematics, 11-16 December, Geneva, 1997. Geneva, World Health Organization, 1998.

9. Augestad KM, Han H, Paige J, et al. Educational implications for surgical telementoring: a current review with recommendations for future practice, 
policy, and research. Surg Endosc 2017;31(10):38363846. https://doi.org/10.1007/s00464-017-5690-y

10. Lee JH, Tanaka E, Woo Y, et al. Advanced real-time multi-display educational system (ARMES): An innovative real-time audiovisual mentoring tool for complex robotic surgery. $J$ Surg Oncol 2017;116(7):894-897. https://doi.org/10.1002/jso.24722

11. Nguyen NT, Okrainec A, Anvari M, et al. Sleeve gastrectomy telementoring: a SAGES multiinstitutional quality improvement initiative. Surg Endosc 2018;32(2):682-687. https://doi.org/10.1007/s00464-017-5721-8

12. Hadley GP, Mars M. e-Education in paediatric surgery: a role for recorded seminars in areas of low bandwidth in sub-Saharan Africa. Pediatr Surg Int 2011;27(4):407-410. https://doi.org/10.1007/s00383010-2806-z

13. Hadley GP, Mars M. Postgraduate medical education in paediatric surgery: Videoconferencing - a possible solution for Africa? Pediatr Surg Int 2008;24(2):223226. https://doi.org/10.1007/s00383-007-2085-5

14. Pradeep PV, Mishra A, Mohanty BN, et al. Reinforcement of endocrine surgery training: impact of telemedicine technology in a developing country context. World J Surg 2007;31(8):1665-1671. https://doi.org/10.1007/s00268-007-9108-1

15. National Knowledge Network. 2016. Available at: http://nkn.gov.in accessed 23 December 2018.

16. Chand G, Agarwal S, Mishra A, et al. The impact of uniform capsular dissection technique of total thyroidectomy on postoperative complications: An experience of more than 1000 total thyroidectomies from an endocrine surgery training centre in North India. Indian J Endocrinol Metab 2018;22(3):362-367. doi: $10.4103 /$ ijem.IJEM $598 \quad 17$

17. Delbridge L, Guinea AI, Reeve TS. Total thyroidectomy for bilateral benign multinodular goiter. Arch Surg 1999;134(12):1389-1393. doi:10.1001/archsurg.134.12.1389

18. Serpell JW, Phan D. Safety of total thyroidectomy. ANZ J Surg 2007;77(1-2):15-19. https://doi.org/10.1111/j.1445-2197.2006.03897.x

19. Bhattacharyya N, Fried MP. Assessment of the morbidity and complications of total thyroidectomy. Arch Otolaryngol Head Neck Surg 2002;128(4):389392. doi:10.1001/archotol.128.4.389

20. Efremidou EI, Papageorgiou MS, Liratzopoulos N, Manolas KJ. The efficacy and safety of total thyroidectomy in the management of benign thyroid disease: A review of 932 cases. Can J Surg 2009;52(1):39-44. PMID: 19234650

21. United Nations, Department of Economic and Social Affairs, Population Division (2015). World Population
Prospects: The 2015 Revision, Key Findings and Advance Tables. Working Paper No. ESA/P/WP.241.

22. Etzioni DA, Liu JH, Maggard MA, Ko CY. The aging population and its impact on the surgery workforce. Ann Surg 2003;238(2)170-177. DOI: 10.1097/01.SLA.0000081085.98792.3d

23. Rahib L, Smith BD, Aizenberg R, et al. Projecting cancer incidence and deaths to 2030: the unexpected burden of thyroid, liver, and pancreas cancers in the United States. Cancer Res 2014;74(14):2913-2921. DOI: 10.1158/0008-5472.CAN-14-0155

24. Saunders BG, Wainess RM, Dimick JB, et al. Who performs endocrine operations in the United States? Surgery 2003;134(6):924-931. https://doi.org/10.1016/S0039-6060(03)00420-3

25. Sosa JA, Wang TS, Yeo HL et al. The maturation of a specialty: workforce projections for endocrine surgery. Surgery 2007;142(6):876-883, https://doi.org/10.1016/j.surg.2007.09.005

26. Ranshaw B, Tucker J, Duncan T. Laparoscopic herniorrhaphy: a review of 900 cases. Surg Endosc 1996;10(1):29-32.

27. Sebajang H, Trudeau P, Dougall A, et al. Telementoring: an important enabling tool for the community surgeon. Surg Innov 2005;12(2):327-331. https://doi.org/10.1177/155335060501200407

28. Oliveira V, Savassi L, Lemos A, Campos F. eLearning for health in Brazil - UNA-SUS in numbers. $J$ Int Soc Telemed eHealth 2016;4:e9.

29. de Oliveira AE, Franca RM, Haddad AE, Brasil LS, Pinho JR. Open applications developed in Brazil for distant learning in dentistry: valuable educational resources for academic professional qualification. $J$ Int Soc Telemed eHealth 2016;4:e10.

30. Chipps J, Ramlall S, Mars M. Videoconference-based education for psychiatry registrars at the University of KwaZulu-Natal, South Africa. Afr J Psychiatry. 2012;15(4):248-254. http://dx.doi.org/10.4314/ajpsy.v15i4.32

31. Mars M. Tele-education in South Africa. Front Public Health 2014;2:173. https://doi.org/10.3389/fpubh.2014.00173

32. The RAFT project on telemedicine in French-speaking Africa. Available at: www.keneya.org.ml accessed

33. Stolyar VL, et al. Experience and perspectives of remote interactive training in medicine, J Int Soc Telemed eHealth 2018;6:e15. https://doi.org/10.29086/JISfTeH.6.e15

34. Simoes N, Coury W, Ribeiro-Filho JL, et al. National Research and Education Networks to support telemedicine and telehealth. J Int Soc Telemed eHealth 2016;4:e8. 